\title{
GARANTISMO À BRASILEIRA: UMA ANÁLISE CRÍTICA À LUZ DA APLICAÇÃO DO PRINCÍPIO DA INSIGNIFICÂNCIA
}

\author{
BRAZILIAN WAY OF GARANTISM: A CRITICAL ANALYSIS IN THE LIGHT OF THE \\ PRINCIPLE OF IMMATERIALITY
}

\author{
Oswaldo Poll Costa* \\ Francisco Quintanilha Veras Neto**
}

\begin{abstract}
RESUMO
Este ensaio busca demonstrar, por meio de pesquisa bibliográfica e de análise jurisprudencial, que o garantismo penal segue uma linha de teorias que foram importadas pelos pensadores nacionais, mas que aqui adquiriram um novo significado, colaborando - diferentemente do que vaticinam em tese mais para a conservação das estruturas fundamentais de nossa sociedade do que para a sua transformação. Não é feita, portanto, uma crítica aos princípios do garantismo penal, mas sim uma análise de como esses princípios vêm sendo utilizados no Brasil. Conclui-se, assim, que quando as garantias constitucionais não são uniformemente asseguradas a todos, elas perdem o seu caráter de garantias, funcionando como uma espécie de privilégio, do qual só gozam com segurança aqueles indivíduos com condições financeiras para custear uma defesa consistente em uma eventual ação penal. Desse modo, o estigma social deixado pelo cárcere acaba recaindo majoritariamente sobre indivíduos pertencentes às camadas mais pobres da população, diminuindo radicalmente qualquer chance de ascensão social dessas pessoas, bem como do grupo social que as rodeia, colaborando, assim, para a manutenção da desigualdade social.
\end{abstract}

\section{PALAVRAS-CHAVE}

Garantismo. Estigma. Desigualdade social.

\begin{abstract}
This essay aims to demonstrate, through bibliographic and case law research, that the criminal garantism follows a current of theories that have been imported by national scholars, but here acquired a new meaning, supporting - contrary to the theses' predictions - the conservation of the fundamental structures of our society instead of its transformation. So it is not a set of criticisms against principles of criminal garantism, but an analysis of how these principles have been used in Brazil. The conclusion is that when constitutional guarantees are not uniformly granted to all, they lose their character of guarantees, functioning as a kind of privilege, enjoyed only by those individuals who have the financial means to afford a consistent defense in an eventual prosecution. Thus, the social stigma left by prison mostly affects those individuals belonging to the poorest sections of the society, decreasing significantly their chances of social mobility, as well as the social group around them, thus contributing to the maintenance of social inequality.

\footnotetext{
* Pós-graduado em Direito Público pela Escola Superior da Magistratura Federal do Rio Grande do Sul. Graduado em Direito pela Universidade Federal do Rio Grande. Graduado em História pela Universidade Federal do Rio Grande. Procurador do Estado do Rio Grande do Sul (Rio Grande, RS, Brasil).E-mail: oswaldopoll@gmail.com

** Pós-Doutor em Direito pela Universidade Federal de Santa Catarina. Doutor em Direito das Relações Sociais pela Universidade Federal do Paraná. Mestre em Direito das Instituições Jurídico-Políticas pela Universidade Federal de Santa Catarina. Professor no Programa de Pós-graduação em Direito e Justiça Social da Universidade Federal do Rio Grande (FADIR) (Rio Grande, RS, Brasil).E-mail: quintaveras@gmail.com
} 


\section{KEYWORDS}

Garantism. Stigma. Social inequality.

\section{INTRODUÇÃO}

Trezentos anos de colonização marcaram de forma indelével a história brasileira. Como é comum nesse tipo de processo histórico - especialmente nas colônias de exploração -, fomos colonizados não só economicamente, mas também culturalmente. A metrópole nos impôs não apenas um modelo produtivo, mas todo um conjunto de instituições e ideias que buscava definir completamente a nossa existência. A produção intelectual no Brasil colônia, apesar de ter existido, nunca foi fomentada por Portugal, tendo sido, mesmo, inibida pela metrópole.

Em uma sociedade polarizada entre senhores e escravos - com clara predominância de um dos polos - e onde o resto, com raras exceções, era apenas o resto, praticamente não havia espaço para o desenvolvimento do espírito. Nossas primeiras instituições políticas, como as capitanias hereditárias, seguiram modelos que já haviam sido aplicados por Portugal em outras colônias. Essa lógica também impregnou o nosso desenvolvimento pós-independência. Tanto no período imperial como no republicano, as teorias que aqui se faziam presentes, bem como as instituições que delas derivavam, eram trazidas dos países europeus ou da América do Norte.

No entanto, nesse tipo de importação nunca houve uma verdadeira preocupação com a fidelidade na aplicação dos princípios que norteavam as linhas teóricas em seus países de origem. Poder-se-ia pensar que a razão desse fenômeno seriam as diferenças entre os contextos sociais local e europeu ou norte-americano, que impedia a fiel aplicação de todos os conceitos em nosso território. Todavia, não é esse o ponto fundamental. De fato, se tivesse havido uma verdadeira preocupação com a realidade local, ter-se-ia facilmente percebido que grande parte das ideias importadas não teria qualquer chance de aqui vingar, sendo principalmente implantadas - como o foram - de modo vertical.

A questão é diversa. A transposição de diversos conjuntos de preceitos ao longo de nossa história não teve um cunho verdadeiramente transformador; ao menos, não no sentido de constituir tentativas de aproximar a sociedade brasileira ao contexto europeu ou norte-americano. O objetivo dos setores da sociedade que promoveram tais importações era meramente legitimar uma realidade social já existente, por meio da invocação de um conjunto de ideias em voga nos países desenvolvidos, ou, mesmo, legitimar alguma mudança ocorrida em nossa sociedade, mas de sentido e amplitude bastante diversos daquelas transformações que levaram à criação das teorias nos países de origem. Desse modo, conceitos como democracia, república e liberalismo, entre outros, foram para cá 
transplantados, sem que houvesse, no entanto, significativas transformações estruturais em nossa sociedade ${ }^{1}$.

Vale frisar que a importação de modelos ou a inspiração em exemplos externos ou antigos é um fenômeno universal. Os próprios pais da pátria norte-americana tiveram como referências ideias e instituições da Antiguidade, da Renascença, da Inglaterra e da França contemporâneas. Também a França revolucionária buscou inspiração nos clássicos e no exemplo estadunidense.

Porém, não é isso que encontramos na experiência brasileira. Aqui, os conceitos não foram construídos - ainda que com inspiração em elementos externos -, como na Europa ou na América do Norte; foram, em vez disso, reproduzidos e utilizados pragmaticamente. No mesmo sentido, a justificação dos regimes não se deu por meio da demonstração ao povo da coerência, da "verdade”, das ideias - até mesmo porque, na maior parte de nossa história, o povo foi deixado à margem dos acontecimentos -, mas sim mediante a utilização da palavra eficaz. As próprias teorias já traziam em seu bojo sua legitimidade, justamente por terem sido produzidas nos grandes centros culturais do mundo. Como utilizá-las em nosso país e que sacrifícios de ordem lógica seriam necessários para tanto eram problemas secundários.

Busca-se, no presente ensaio, traçar uma aproximação entre os processos históricos acima mencionados e a práxis do garantismo penal no Brasil. Cabe, aqui, uma breve digressão sobre o termo práxis $^{2}$, no sentido utilizado no presente trabalho.

Para Marx, a realidade é produto da atividade concreta do homem e não de uma atividade pensante, como defendido pelos idealistas. Assim, Marx vai transferir o princípio da práxis da concepção abstrata do espírito para a atividade humana material e social concreta de transformação da realidade objetiva da natureza, da sociedade e do próprio homem. A atividade humana torna-se a reconciliação da teoria e da práxis. Toda a teoria é teoria da práxis. Exprime a unidade dialética do pensar e do ser, sendo ao mesmo tempo saber e prática, conhecimento e ação. É o termo natural da teoria, sem o qual esta seria inútil.

O termo práxis, portanto, exprime a ideia da ação que não prescinde da teoria. É precisamente esse o motivo de sua utilização. A crítica aqui realizada ao garantismo penal tem como foco justamente a forma como os princípios, há décadas construídos pelos pensadores desta linha,

\footnotetext{
${ }^{1}$ Diversas obras da historiografia nacional tratam do tema. Entre elas, Raízes do Brasil, de Sérgio Buarque de Holanda, A formação das almas, de José Murilo de Carvalho, e Os donos do poder, de Raymundo Faoro.

${ }^{2}$ Com essa palavra (que é a transcrição do termo grego para ação), a terminologia marxista designa o conjunto de relações de produção e trabalho, que constituem a estrutura social, e a ação transformadora que a revolução deve exercer sobre tais relações. Marx dizia que é preciso explicar a formação das ideias a partir da "práxis material”, e que, por conseguinte, formas e produtos da consciência só podem ser eliminados por meio da "inversão prática das relações sociais existentes”, e não por meio da “crítica intelectual” (ABBAGNO, 2012, p. 922).
} 
vêm sendo aplicados em nosso país. Não se pretende, portanto, criticar a produção teórica dos autores garantistas nacionais, mas analisar como os conceitos por eles enunciados - frise-se, sempre embasados nos grandes nomes do garantismo penal europeu - são utilizados no dia a dia do Poder Judiciário, bem como nas fases preliminares de investigação.

Assim, em um primeiro momento, são utilizados os conceitos expostos por diversos autores desta linha, tanto europeus quanto nacionais, no sentido de demonstrar que alguns dos alicerces do garantismo penal - entre eles, a presunção de inocência - têm como um de seus fundamentos a desigualdade de forças entre os atores do processo penal - o Estado-acusador e o indivíduo-acusado. É feita, então, uma crítica desta premissa, bem como uma análise sobre a diferença no tratamento recebido pelos réus em nosso sistema penal. Para tanto, é analisado o conteúdo de diversos julgados, com um foco especial na aplicação do princípio da insignificância no Tribunal de Justiça do Rio Grande do Sul.

\section{FUNDAMENTOS TEÓRICOS: A DESIGUALDADE ENTRE ESTADO-ACUSADOR E INDIVÍDUO-ACUSADO}

A teoria do garantismo ultrapassa em muito o âmbito do Direito Penal e Processual Penal. É fácil perceber isso, pois, do ponto de vista lógico, ao falar-se em garantias constitucionais não se está designando apenas aquelas que o indivíduo possui quando está na posição de acusado ou de réu em um processo penal. No Brasil, por exemplo, a propriedade é um direito fundamental, previsto constitucionalmente, bem como o são os remédios constitucionais para defendê-la. Ainda que seja possível que o direito à propriedade seja invocado por um acusado no caso de serem tomadas medidas constritivas de seu patrimônio dentro de uma investigação policial ou de um processo penal, na absoluta maioria das vezes em que o referido direito é defendido, judicialmente ou não, a lesão ou ameaça a esse direito nada tem a ver com o Direito Penal.

Luigi Ferrajoli (2012) distingue três significados para o constitucionalismo garantista: modelo ou tipo de sistema jurídico, teoria do direito e filosofia política. No primeiro, o constitucionalismo garantista se caracteriza, com relação ao que ele chama de “paleo-juspositivismo”, pela positivação também dos princípios que devem subjazer toda a produção normativa. No segundo, ou seja, como teoria do direito, o constitucionalismo garantista tematiza a divergência entre o dever ser (constitucional) e o ser (legislativo) do direito, caracterizando-se pela distinção entre validade e vigência, já que admite a existência de normas vigentes ainda que inválidas, pois, apesar de terem sido produzidas de acordo com as normas procedimentais sobre a sua formação, são incompatíveis com as normas substanciais previstas constitucionalmente. Por fim, como filosofia política, o

Revista da Faculdade de Direito - UFPR, Curitiba, vol. 61, n. 3, set./dez. 2016, p. 165 - 187 
constitucionalismo garantista consiste em uma teoria da democracia. Não apenas uma abstrata teoria do bom governo, mas sim uma teoria da democracia substancial, além de formal, ancorada empiricamente no paradigma de governo por ele apresentado.

Todavia, especialmente no Brasil, os ramos do direito em que o garantismo obteve maior aceitação são, sem dúvida, o Direito Penal e o Direito Processual Penal. As garantias dadas aos réus no processo penal são fruto de uma longa evolução histórica, na qual se percebeu que a violência perpetrada pelo Estado, apesar de ser a única legítima, é provavelmente a mais injusta, dada a desigualdade de forças entre as partes - Estado $x$ cidadão (WEBER, 1982, p. 55). De fato, a ideia de que o chamado Estado de Direito existe para proteger o indivíduo contra os arbítrios do poder estatal é cara a todos os ramos do direito público. Celso Antônio Bandeira de Mello (2014, p. 332) afirma que “A razão mesma do Estado de Direito é a defesa do indivíduo contra o poder público”, asseverando, ainda, que a fórmula, por excelência, garantidora desse intento é a tripartição do exercício do Poder; graças a ela os cidadãos se garantem ante os riscos de demasias do Executivo, negando-lhe qualquer força jurídica para estabelecer regras que impliquem limitações à liberdade e propriedade das pessoas. Foi justamente para deter o poder do monarca, cujo sucessor é o Poder Executivo, que se concebeu esse mecanismo, amplamente difundido no mundo atual.

A teoria do Garantismo Penal também se estruturou sobre essas proposições. Dessa forma, o mesmo conjunto de ideias é explicitado também em diversas obras de importantes doutrinadores do garantismo. É sintomático, nesse sentido, que Cezar Roberto Bitencourt chame o capítulo referente aos princípios do Direito Penal, em seu Tratado de Direito Penal, de "Princípios limitadores do poder punitivo estatal” (BITENCOURT, 2015). No mesmo sentido, Cláudio Brandão (2010, p. 49-50), ao dissertar sobre a relação entre Direito Penal e Estado de Direito, afirma que

[...] o Princípio da Legalidade constitui-se em um limite da intervenção estatal, sendo indissociável da ideia do Direito Penal de um Estado Social e Democrático de Direito. A legalidade preserva a liberdade e a dignidade do homem, e assegura que esses valores não sejam arbitrariamente violados pelo jus puniendi do Estado.

Cite-se, ainda, o seguinte trecho, da obra Processo Penal e sua Conformidade Constitucional, de Aury Lopes Júnior (2011, p. 12-14):

W. Goldschmidt explica que os direitos fundamentais, como tais, dirigem-se contra o Estado, e pertencem, por conseguinte, à seção que trata do amparo do indivíduo contra o Estado. O processo penal constitui um ramo do Direito Público, e, como tal, implica autolimitação do Estado, uma soberania mitigada. Ademais, existe ainda o fundamento histórico-político para sustentar a dupla função do moderno processo penal, que foi bem abordado por Bettiol. [...] Por isso, Ferrajoli fala da ley Del más débil. No momento do crime, a vítima é o débil e, por isso, recebe a tutela penal. Contudo, no processo penal opera-se uma importante modificação: 
o mais débil passa a ser o acusado, que frente ao poder de acusar do Estado sofre a violência institucionalizada do processo e, posteriormente, da pena.

Construiu-se, assim, toda uma teoria - ou teorias - que baliza o raciocínio de que a aplicação da violência estatal, para ser legitimada, tem que ser precedida de um processo. No trecho acima, Aury Lopes Júnior cita uma importante ideia trazida por Luigi Ferrajoli. De fato, não há como falar sobre o tema sem discutir, ainda que brevemente, alguns conceitos apresentados por este, especialmente em sua obra basilar sobre o tema, Direito e Razão. Ferrajoli (2014, p. 450) afirma que o processo penal existe não para proteger a vítima ou a sociedade, de maneira geral, contra a criminalidade, mas sim o acusado, justamente por ser este - como dito acima - o mais débil em sua relação com o Estado. Desse modo, o processo penal não serve para proteger a maioria, mas sim para proteger, ainda que contra a maioria, aqueles cidadãos individualizados que, não obstante suspeitos, não podem ser ditos culpados sem provas.

No entanto, dentro dessa ótica, não é qualquer tipo de processo que é capaz de legitimar a violência perpetrada pelo Estado. É necessário que seja seguido um sistema acusatório, garantindose ao acusado uma série de direitos. Entre estes, um dos principais é a garantia à presunção de inocência, ou seja, cabe ao Estado - nos casos de ação penal de iniciativa pública - provar que determinado indivíduo é culpado, sendo que a inércia de ambas as partes levaria, logicamente, à absolvição: "Sendo a inocência assistida pelo postulado de sua presunção até prova em contrário, é essa prova contrária que deve ser fornecida por quem a nega formulando a acusação. Daí o corolário do ônus acusatório da prova expresso pelo nosso axioma A9 nulla accusatio sine probatione” (FERRAJOLI, 2014, p. 488).

É claro que a violência estatal também se verifica em outras áreas do direito. Em uma reintegração de posse de uma área pública, por exemplo, pode ser usada força policial. Na desapropriação de bens por utilidade pública, ainda que seja mediante prévia indenização, há a perda da propriedade, direito fundamental previsto constitucionalmente. No entanto, o Direito Penal é o ramo do direito que lida com as maiores restrições que o Estado pode impor aos indivíduos. Em nosso país, como são constitucionalmente vedadas penas cruéis ou a pena de morte - exceto em caso de guerra declarada -, como em qualquer sistema penal garantista, a pena de prisão é a pena por excelência.

Sobre o ponto, explica Salo de Carvalho, ao comentar os conceitos enunciados por Beccaria, que a estrutura penal baseada na teoria do contrato social impossibilita o Estado de executar aquilo que não foi previamente acordado e que não seria exigível que cada indivíduo cedesse mais do que uma parte do bem jurídico liberdade. Desse modo, a incidência da pena sobre qualquer outro bem

Revista da Faculdade de Direito - UFPR, Curitiba, vol. 61, n. 3, set./dez. 2016, p. 165 - 187 
jurídico, como a vida, por exemplo, seria ilegítima: “Não se pode, portanto, neste modelo, deliberar sobre a vida de um cidadão; somente sua liberdade (parcial) poderia ser negociada, sujeitando-a à sanção. Mais: a esfera da liberdade diria respeito tão-somente à liberdade de locomoção" (CARVALHO, 2008, p. 123).

É com o constante risco da perda da liberdade que os acusados têm que lidar no processo penal. No entanto, segundo Ferrajoli, um inocente não poderia jamais ter esse tipo de temor, já que a prisão de um indivíduo que não é culpado é uma das maiores representações do arbítrio do poder estatal. Para esse autor, apenas a desconfiança de um inocente já é capaz de retirar a legitimidade de todo o sistema:

\begin{abstract}
Disso decorre - se é verdade que os direitos dos cidadãos são ameaçados não só pelos delitos mas também pelas penas arbitrárias - que a presunção de inocência não é apenas uma garantia de liberdade e de verdade, mas também uma garantia de segurança ou, se quisermos, de defesa social: da específica "segurança” fornecida pelo Estado de direito e expressa pela confiança dos cidadãos na justiça, e daquela específica “defesa” destes contra o arbítrio punitivo. Por isso, o sinal inconfundível da perda de legitimidade política da jurisdição, como também de sua involução irracional e autoritária, é o temor que a justiça incute nos cidadãos. Toda vez que um imputado inocente tem razão de temer um juiz, quer dizer que isto está fora da lógica do Estado de Direito: o medo e mesmo só a desconfiança ou a não segurança do inocente assinalam a falência da função mesma da jurisdição penal e a ruptura dos valores políticos que a legitimam (FERRAJOLI, 2014, p. 441).
\end{abstract}

A justificativa moral do garantismo reside, portanto, na contenção do poder punitivo estatal, que decorre do reconhecimento da desigualdade de forças entre as partes envolvidas na relação Estado $x$ Indivíduo. Esta ideia é bem sintetizada pelo pensador italiano Norberto Bobbio que, não por acaso, foi o escolhido para escrever o prefácio da primeira edição de Direito e Razão. Em ensaio intitulado Contra a Pena de Morte, Bobbio defende que o Estado não pode colocar-se no mesmo plano do indivíduo singular. O indivíduo age por raiva, por paixão, por interesse, em defesa própria, já o Estado responde de modo mediato, reflexivo, racional, ainda que também tenha o dever de se defender. Todavia, por ser muito mais forte do que o indivíduo singular, não tem necessidade de tirar a vida desse indivíduo para se defender: o Estado tem o privilégio do monopólio da força e deve sentir toda a responsabilidade desse privilégio (BOBBIO, 2004, p. 181).

Vê-se, portanto, que um dos principais objetivos do garantismo é conter o arbítrio estatal, especialmente naquele campo em que o Estado está mais propenso a praticá-lo: o Direito Penal. Necessário notar, todavia, que essa tarefa cabe, em grande parte, ao próprio Estado, mediante a atuação de órgãos do Poder Executivo, do Ministério Público, da elaboração de normas pelo Legislativo e, principalmente, por meio do Poder Judiciário. Cite-se, por exemplo, a função de garante 
que deve ocupar o juiz durante o inquérito policial ${ }^{3}$, ou, ainda, a função de guardião da Constituição do Supremo Tribunal Federal.

Ora, por que deve o Estado conter o próprio poder punitivo estatal? A resposta é simples: porque ele é o único capaz de fazê-lo. A ideia que temos do Estado Moderno deve muito à obra dos contratualistas dos séculos XVII e XVIII - Locke, Hobbes e Rousseau. Mesmo que os séculos XIX e XX tenham nos dado notáveis exemplos de pensadores que defendem a tese de uma sociedade capaz de opor-se ao Estado ${ }^{4}$, o Garantismo Penal parte da concepção tradicional, na qual as pessoas abrem mão da liberdade inerente ao estado de natureza em troca da segurança proporcionada pelo Estado. As constantes referências aos textos de Hobbes na obra de Ferrajoli ${ }^{5}$ deixam isso evidente. Para compreender qual seria o poder do Estado dentro dessa concepção, basta citar um trecho da obra Leviatã:

Isto é mais do que consentimento, ou concórdia, é uma verdadeira unidade de todos eles, numa só e mesma pessoa, realizada por um pacto de cada homem com todos os homens, de um modo que é como se cada homem dissesse a cada homem: Cedo e transfiro meu direito de governar-me a mim mesmo a este homem, ou a esta assembléia de homens, com a condição de transferires a ele teu direito, autorizando de maneira semelhante todas as suas ações. Feito isto, à multidão assim unida numa só pessoa se chama Estado, em latim civitas. É esta a geração daquele grande Leviatã, ou antes (para falar em termos mais reverentes) daquele Deus Mortal, ao qual devemos, abaixo do Deus Imortal, nossa paz e defesa. Pois graças a esta autoridade que lhe é dada por cada indivíduo no Estado, é-lhe conferido o uso de tamanho poder e força que o terror assim inspirado o torna capaz de conformar as vontades de todos eles, no sentido da paz em seu próprio país, e da ajuda mútua contra os inimigos estrangeiros (HOBBES, 2003, p. 153).

Nota-se, portanto, que Hobbes não fala de uma sociedade em que os indivíduos cedem apenas uma pequena parte de sua liberdade em troca dos benefícios proporcionados pelo Estado. Defende, sim, o referido pensador a ideia de um Estado todo-poderoso, que reúne toda força e poder dos indivíduos que compõem a sociedade.

Dentro dessa ótica, não há falar em igualdade - seja no plano material ou processual - entre o Estado todo-poderoso (acusação) e o indivíduo (defesa) e, de fato, não há que se cogitar, em nosso sistema processual penal, a igualdade entre as partes. Enquanto no processo civil diversos autores defendem uma lógica dinâmica de produção das provas ${ }^{6}$, no sistema processual penal garantista é

\footnotetext{
${ }^{3}$ Sobre o tema, a obra de Aury Lopes Jr., intitulada Investigação preliminar no processo penal, na qual o autor explica a função do juiz garantidor.

${ }^{4}$ Ver, principalmente, o texto de Henry Thoreau, A desobediência civil, e a obra de Pierre Clastres intitulada A sociedade contra o Estado.

${ }^{5}$ Apenas no cap. 8 da obra Direito e razão (intitulado O delito. Quando e como proibir), de cerca de 40 páginas, Ferrajoli faz dez referências à obra de Hobbes.

${ }^{6}$ Sobre o tema, cite-se exemplificativamente a obra de Luiz Guilherme Marinoni e Daniel Mitidiero, O Projeto do CPC: crítica e propostas.
}

Revista da Faculdade de Direito - UFPR, Curitiba, vol. 61, n. 3, set./dez. 2016, p. 165 - 187 
inquestionável que o ônus probatório cabe à acusação. A desigualdade no plano processual vem diretamente da desigualdade no plano fático. A racionalidade que daí transparece é a de que o Estado todo-poderoso teria muito mais condições de obter meios de prova do que qualquer cidadão e, considerando que o Direito Penal lida com os bens jurídicos mais importantes (não somente com relação às vítimas, mas também no que concerne aos acusados), é justamente nesse campo em que o poder estatal deve demonstrar com mais clareza que sua atuação é legítima. Justifica-se, desse modo, a presunção de inocência dos indivíduos e o consequente deslocamento de toda a carga processual para a acusação.

\section{O CONTEXTO BRASILEIRO}

Não obstante a inegável correção dessas proposições, quando analisamos essa situação em um país em desenvolvimento, como o Brasil, onde a polícia judicial possui parcos meios de investigação (sem adentrar no mérito da corrupção policial) e o Ministério Público, apesar de muito mais bem aparelhado, tem que lidar com um número infindável de processos, é cabível questionar se, para parte da população - deixemos claro, os setores economicamente mais favorecidos - essa lógica não acaba por se inverter. Será que as instituições encarregadas de promover a acusação têm mesmo melhores condições de obter meios de prova em cada investigação do que qualquer cidadão? Lembrese dos honorários elevadíssimos que recebem os grandes escritórios de advocacia, o que lhes possibilita trabalhar com um número bastante reduzido de processos, bem como dos recursos financeiros que possuem alguns réus, o que lhes permite contratar especialistas, como peritos e até mesmo investigadores particulares.

Ou seja, as inúmeras garantias processuais dadas aos réus se converteriam, nesses casos, em verdadeiros privilégios (no sentido de algo inverso ao direito), que desequilibrariam ainda mais uma balança que já estava inclinada para o seu lado. Cabe lembrar, ainda, dos pedidos e recursos procrastinatórios, utilizados - diga-se de passagem, com grande habilidade - por muitos advogados, visando alcançar a consumação do prazo prescricional.

Os argumentos até aqui apresentados poderiam até mesmo, em uma análise superficial, soar como algo positivo, se pensarmos dentro de uma lógica de redução da cultura punitiva. No entanto, é aí que surge a maior distorção da lógica do direito/processo penal em nosso país. As garantias, especialmente as de cunho processual, têm pouca valia para aqueles que não têm recursos suficientes para custear os honorários de profissionais (muito) bem qualificados. A maioria dos réus é atendida por advogados mal preparados ou pela defensoria pública, que, se comparada aos grandes escritórios 
de advocacia ou ao Ministério Público, possui uma estrutura precária.

Necessário recordar que uma das marcas de nossa sociedade durante toda a história do Brasil pós-descobrimento foi a grande desigualdade social, a qual mantém uma relação dialética com o precário acesso, por boa parte da população, à justiça. Gizlene Neder (2012, p. 80) nos lembra que o “autoritarismo sempre esteve presente nas relações sociais basilares da formação histórica brasileira”. Em uma sociedade fortemente estratificada, em que o acesso à cultura, à educação e aos bens de consumo sempre esteve amplamente disponível apenas para uma pequena parte dos cidadãos, o acesso ao Judiciário também reflete a desigualdade e a tradição autoritária de nossa nação.

Sublinhe-se que, no quadro de valores de um país profundamente marcado pela mentalidade e pelas estruturas sociais erigidas durante o período da escravidão, a noção de ordem ganha mais relevo que a de justiça, com a prevalência de uma expectativa de obediência passiva (NEDER, 2000, p. 194). Ou seja, o sistema penal estruturado no Brasil tem servido como um instrumento para a manutenção do status quo. Frise-se, não apenas à manutenção da ordem pública, como em qualquer sistema penal, mas para a sustentação das estruturas de uma sociedade extremamente desigual, tendo o garantismo penal encontrado seu lugar dentro dessa lógica.

Apesar da diferença no tratamento recebido pelos “clientes” - de acordo com o seu nível social - do sistema penal em nosso país ser amplamente conhecida ${ }^{7}$, sua demonstração prática não é simples. Basta lembrar que grande parte dos processos criminais tramita com algum nível de sigilo, bem como qualquer documento que diga respeito às condições financeiras dos indivíduos, como documentos fiscais.

Entretanto, a grande disparidade entre as decisões proferidas pelo Poder Judiciário em nosso país já deixa claro que as garantias constitucionais estão longe de serem asseguradas de maneira uniforme a todos os réus. Citem-se como exemplo as diferenças entre as decisões proferidas pelas câmaras criminais do Tribunal de Justiça do Rio Grande do Sul (TJRS) no que se refere à aplicação do princípio da insignificância - excludente de tipicidade que enseja a absolvição do réu. Uma simples pesquisa jurisprudencial no site do TJRS é capaz de demonstrar isso. Consultados os trinta primeiros resultados referentes à $5^{\mathrm{a}}$ e à $7^{\mathrm{a}}$ câmaras criminais do referido tribunal, relacionados à aplicação do princípio da bagatela no que concerne ao crime de furto ${ }^{8}$, o resultado obtido foi que, na 5a Câmara Criminal, em 24 acórdãos foi reconhecida a aplicabilidade do princípio da insignificância ao caso concreto, enquanto em seis acórdãos foi proferido o entendimento de que não deveria ser

\footnotetext{
${ }^{7}$ Máximas muito comuns como "só pobre vai pra cadeia” demonstram que o tratamento diferenciado recebido pelos setores mais abastados faz parte do imaginário popular.

${ }^{8}$ Pesquisa realizada com os termos “insignificância” e “furto”, no site do TJRS, referente a 8 ago. 2012.
}

Revista da Faculdade de Direito - UFPR, Curitiba, vol. 61, n. 3, set./dez. 2016, p. 165 - 187 
aplicado o referido princípio. Já com relação à $7^{\text {a }}$ Câmara Criminal, em nenhum dos trinta acórdãos consultados foi reconhecida a aplicabilidade do princípio da bagatela.

Essa discrepância poderia ser apenas fruto de uma coincidência, já que os casos analisados pelos órgãos colegiados da mencionada corte não são, obviamente, idênticos. Poderia ter ocorrido, portanto, que nos trinta últimos acórdãos publicados os casos analisados pela $7^{\text {a }}$ Câmara Criminal fossem de delitos mais graves do que os referentes aos acórdãos proferidos pela $5^{\text {a }}$ Câmara. Todavia, a análise detalhada de alguns dos julgados demonstra o contrário.

O julgamento referente ao Processo n ${ }^{0} 70048499164$ recebeu a seguinte ementa:

APELAÇÃO CRIME. CRIMES CONTRA O PATRIMÔNIO. FURTO. PRINCÍPIO DA INSIGNIFICÂNCIA. INAPLICABILIDADE. CONDENAÇÃO MANTIDA. PENAS REDIMENSIONADAS. Os elementos de convicção colhidos durante a instrução demonstram a materialidade e a autoria do crime de furto simples. Inviável a absolvição fundada na incidência do princípio da insignificância, considerando que os objetos subtraídos foram avaliados em quantia equivalente a $25 \%$ do valor do salário-mínimo vigente ao tempo do fato. Da mesma forma, o réu é reincidente em crimes diversos. Tais informações, analisadas em conjunto, não permitem a aplicação da benesse. Penas redimensionadas. APELAÇÃO PARCIALMENTE PROVIDA. (Apelação Crime No 70048499164, Sétima Câmara Criminal, Tribunal de Justiça do RS, Relator: Naele Ochoa Piazzeta, Julgado em 19/07/2012) Data de Julgamento: 19/07/2012 Publicação: Diário da Justiça do dia 25/07/2012).

O relatório do referido decisum evidencia, ainda, que o condenado subtraiu mercadorias de um supermercado, que, somadas, perfaziam um total de R\$ 138,53 (cento e trinta e oito reais e cinquenta e três centavos), conforme auto de avaliação, e que os objetos furtados foram apreendidos e devolvidos à vítima. Por sua vez, o acórdão proferido pela 5ª Câmara Criminal do TJRS no Processo $n^{0} 70044378354$ recebeu a seguinte ementa:

FURTO. PRINCÍPIO DA INSIGNIFICANCIA. ABSOLVIÇÃO. O valor dos bens subtraídos, avaliados em R \$ 180,00, a restituição das "res furtivae” à vítima, que não sofreu qualquer prejuízo e a pouca repercussão social do delito, frente à consequência para a vida do acusado da condenação, conduzem à convicção que deve ser acolhida a insignificância como suporte à absolvição do réu, com base no art. 386, inciso III, do Código de Processo Penal. RECURSO DEFENSIVO PROVIDO. (Apelação Crime N 70044378354, Quinta Câmara Criminal, Tribunal de Justiça do RS, Relator: Genacéia da Silva Alberton, Julgado em 04/07/2012).

Ou seja, em ambos os casos o produto do crime foi devolvido à vítima, tendo os delitos, de fato, características bastante semelhantes. Porém, no caso julgado pela $5^{\text {a }}$ Câmara Criminal o valor das mercadorias furtadas foi superior ao dos bens referentes ao caso decidido pela $7^{\text {a }}$ Câmara e, mesmo assim, a primeira decidiu pela aplicabilidade do princípio da insignificância, enquanto a segunda entendeu ser inviável a sua aplicação.

Do mesmo modo, no Processo $n^{0} 70048707111$ a $7^{\text {a }}$ Câmara Criminal entendeu que: “O 
princípio da insignificância não pode ser aplicado ao caso em tela, uma vez que o bem subtraído foi avaliado em quantia que não pode ser entendida como ínfima ou irrisória”. A análise do relatório do acórdão revela que foi furtada mercadoria de um supermercado, no valor de R\$ 150,00 (cento e cinquenta reais), bem como que o produto do crime foi apreendido pela Brigada Militar e devolvido à vítima. Já a $5^{\mathrm{a}}$ Câmara Criminal explicitou, no julgamento do Processo $\mathrm{n}^{\mathrm{o}}$ 70049438658, entendimento no sentido de estar ausente “[...] a lesividade na conduta descrita na denúncia, dado que, aliado ao inócuo valor do bem subtraído, conforta a conclusão pelo reconhecimento do princípio da insignificância pela atipicidade do agir do apelante”. Nesse caso, segundo o relatório elaborado pelo relator, foi furtada mercadoria de estabelecimento comercial, avaliada em $\mathrm{R} \$ 250,00$ (duzentos e cinquenta reais), que posteriormente foi apreendida e devolvida ao dono. Novamente, percebe-se que os fatos analisados são muito semelhantes e que o valor da mercadoria furtada é menor no caso julgado pela $7^{\text {a }}$ Câmara Criminal. Entretanto, mais uma vez, apenas a $5^{\text {a }}$ Câmara Criminal reconheceu a aplicabilidade do princípio da bagatela.

Fica claro, portanto, que a diferença não reside nas características dos casos julgados, mas sim na linha seguida pelos julgadores, que fez com que a $7^{\text {a }}$ Câmara Criminal do Tribunal de Justiça do Rio Grande do Sul não reconhecesse a possibilidade de aplicação do princípio da insignificância em nenhum dos trinta acórdãos consultados, enquanto a $5^{\text {a }}$ Câmara entendeu pela aplicabilidade do referido princípio em 24 processos, ou seja, 80\% dos casos analisados.

Mesmo que essa disparidade não tenha, em princípio, nenhuma relação com a condição financeira dos réus envolvidos nos processos, é necessário lembrar que a maioria das questões relacionadas ao Direito Penal no Brasil tem implicações constitucionais, o que permite, em tese, a interposição de recursos e outras formas de impugnação até mesmo no Supremo Tribunal Federal. Entretanto, as regras processuais vigentes, presentes na legislação ou nos regimentos internos das cortes, criam uma série de empecilhos ao acesso aos tribunais superiores - por razões óbvias, já que nestes seria inviável a análise de todos os processos em trâmite no País -, somente superada, em regra, por advogados hábeis e com bom trânsito nos respectivos tribunais.

Desse modo, mesmo que não haja, em um primeiro momento, qualquer conexão entre a condição financeira dos réus e a diferença de tratamento dado a eles - como provavelmente ocorre no exemplo acima citado -, o acesso restrito aos tribunais superiores, que poderia assegurar o respeito às garantias constitucionais dos réus, faz com que apenas uma pequena parcela dos acusados tenha, de fato, seus direitos fundamentais garantidos.

Outra forma de demonstrar a diferença de tratamento recebida por alguns réus é a análise de decisões, proferidas pelos tribunais pátrios, que fogem do padrão jurisprudencial dos mesmos. Um 
exemplo interessante é o caso dos crimes societários ou de autoria coletiva. A jurisprudência do Tribunal Regional Federal da $4^{a}$ Região (TRF4) é pacífica no sentido de que, nesse tipo de delito, não há a necessidade da descrição detalhada de cada um dos réus na denúncia. Cite-se, nesse sentido, o seguinte trecho, da ementa do Habeas Corpus n 2007.04.00.017910-9: “Nos crimes societários não há necessidade de uma descrição detalhada da conduta de cada um dos réus” (TRF4, HC 2007.04.00.017910-9, Oitava Turma, D.E. 09/04/2008), ou, ainda, o seguinte excerto, retirado da ementa da Apelação Criminal n 2002.70.03.000849-8: “[...] a jurisprudência é pacífica no sentido de que, nos crimes societários ou de autoria coletiva, não é necessário que a denúncia descreva, pormenorizadamente, a ação de cada denunciado” (TRF4, ACR 2002.70.03.000849-8, Oitava Turma, D.E. 18/04/2007). Na mesma esteira, exemplificativamente, vão os julgados proferidos na ACR 5016537-37.2010.404.7000, Sétima Turma, D.E. 01/06/2012; na ACR 5016548-66.2010.404.7000, Sétima Turma, D.E. 01/06/2012; e na ACR 2003.72.02.000014-1, Oitava Turma, D.E. 10/05/2012.

Entretanto, no Habeas Corpus $\mathrm{n}^{\mathrm{o}}$ 0005475-02.2011.404.0000, relatado pelo mesmo desembargador do HC e da Apelação Criminal cujos trechos foram acima citados, foi proferida decisão nos seguintes termos:

\footnotetext{
A circunstância de se cuidar de uma suposta sonegação fiscal empresarial exige da acusação descrição dos elementos objetivos e subjetivos da prática delituosa. É preciso definir, com base em evidências sólidas, a verdadeira posição daqueles que se pretende acusar, especialmente neste caso, em que envolvidas sociedades mercantis com um quadro administrativo sabidamente complexo.
}

Fica claro que, nessa causa, patrocinada por um conhecido escritório do estado de Santa Catarina, o entendimento aplicado foi completamente diferente do apresentado nos casos anteriores. Desnecessário dizer que a obtenção de decisão que se opõe ao entendimento que vem sendo adotado pelo TRF4 exigiu, certamente, grande habilidade do procurador dos réus na exposição dos fatos.

É nos casos de grande repercussão, entretanto, que fica mais clara a falta de coerência de nosso sistema punitivo. Enquanto pessoas ainda são presas e condenadas por roubar gêneros alimentícios, provas obtidas por meio de grandes operações da Polícia Federal são anuladas por meras irregularidades, deixando sem qualquer punição os envolvidos.

Não há que se pensar, entretanto, que este é um caso isolado. De fato, a maioria dos casos supramencionados, nos quais a $7^{\text {a }}$ Câmara Criminal do Tribunal de Justiça do Rio Grande do Sul entendeu não ser devida a aplicação do princípio da insignificância, refere-se a pequenos furtos. Em um, inclusive, foram levados apenas alguns desodorantes e barras de chocolate.

Em contrapartida, todas as provas produzidas na Operação Satiagraha, realizada pela Polícia Federal, foram anuladas pelo Superior Tribunal de Justiça, devido à "participação indevida, 
flagrantemente ilegal e abusiva, da ABIN”. Complementa, ainda, o relator do Habeas Corpus $\mathrm{n}^{\circ}$ 149250/SP: "Não há se falar em compartilhamento de dados entre a ABIN e a Polícia Federal, haja vista que a hipótese dos autos não se enquadra nas exceções previstas na Lei n 9.883/99”. Causa ainda maior estranheza a referida decisão quando analisada paralelamente a outras, também proferidas pelo mesmo órgão colegiado - a Quinta Turma do Superior Tribunal de Justiça. Cite-se, nesse sentido, o seguinte aresto:

PROCESSO PENAL. ADMISSÃO DO ASSISTENTE DE ACUSAÇÃO. INTIMAÇÃO PARA PARTICIPAR DO PROCESSO. AUSÊNCIA. ATOS INSTRUTÓRIOS PRATICADOS POR ASSISTENTE DESCONSTITUÍDO EM VIRTUDE DE SUPERVENIÊNCIA DE NOVO MANDATO. NULIDADE. ALEGAÇÃO. INEXISTÊNCIA DE PREJUÍZO PARA A DEFESA. AGRAVO DESPROVIDO. 1. A ausência de admissão ou intimação do novo assistente da acusação para participar do processo, assim como a presença do antigo assistente nos atos processuais não trouxe qualquer prejuízo à defesa, de forma que não se mostra prudente anular a ação penal em virtude de mera irregularidade. 2. Mesmo considerando que o vício citado acarretou prejuízo, este se deu em relação à própria acusação, não cabendo à defesa arguí-la, conforme dispõe o art. 565, do Código de Processo Penal. 3. Agravo regimental desprovido. (AGRESP 200700841625, JORGE MUSSI, STJ - QUINTA TURMA, DJE DATA:16/11/2010)

Necessário mencionar, ainda, trecho do relatório referente ao mencionado decisum:

Segundo o agravante, a decisão objurgada incorreu em erro ao negar seguimento ao seu recurso especial, haja vista que a assistente da acusação, Dra. Nara Rúbia, mesmo após ter substituído o assistente anterior, não teria praticado nenhum ato processual no curso do processo. Desta forma, seriam absolutamente viciados os atos em que houve intervenção do assistente de acusação já desconstituído, Dr. João Estrela e Silva, tais como as audiências de instrução.

Ou seja, o mesmo órgão que entendeu tratar-se de mera irregularidade a participação, em diversos atos processuais, inclusive audiências de instrução, de assistente de acusação já desconstituído - tendo participado, portanto, diretamente da produção das provas durante o processo -, considerou "flagrantemente ilegal e abusiva” a simples participação de agentes da ABIN ainda durante a fase de investigação policial, referente à Operação Satiagraha, fato este capaz de gerar a nulidade de todas as provas produzidas durante a referida operação. Lembre-se que um dos principais investigados na Operação Satiagraha era o banqueiro Daniel Dantas, defendido por Andrei Zenkner Schmidt.

Em artigo intitulado Prevencionismo x Humanitarismo: Uma Perspectiva SistêmicoCultural do Direito Penal, Andrei Schmidt (2004, p. 151) escreve que:

Uma apreciação despreconceituosa da intervenção penal é capaz de demonstrar que o Direito penal, como bem destacaram Hulsman e Zaffaroni, é um sistema fadado à ineficácia: se a lei

Revista da Faculdade de Direito - UFPR, Curitiba, vol. 61, n. 3, set./dez. 2016, p. 165 - 187 
penal fosse aplicada a todos os fatos concretos que a enquadrassem no espectro da norma, a imensa maioria da população seria condenada criminalmente diversas vezes por ano. Consequentemente, o Direito penal seleciona arbitrariamente suas vítimas, revelando-se, pois, a nítida distinção entre ser criminoso e ser criminalizado: quem pode mais enquadra-se no primeiro grupo; quem pode menos, no segundo.

É interessante notar como um autor que percebe tão claramente que a questão do poder do indivíduo influencia decisivamente no tratamento que este recebe quando em contato com o sistema punitivo é o mesmo que, ao atuar como advogado, se utiliza do arsenal teórico do garantismo para assegurar que seu cliente - aquele que “pode mais” - seja absolvido.

Outro caso que ganhou considerável notoriedade foi a anulação do recebimento da denúncia na Ação Penal n. ${ }^{o}$ 2009.61.81.006881-7, também pelo Superior Tribunal de Justiça, por considerar inválidas as provas produzidas durante a operação, da Polícia Federal, intitulada "Castelo de Areia”, que envolveu o nome de diversos congressistas brasileiros. A decisão proferida pelo STJ foi assim ementada:

HABEAS CORPUS. "OPERAÇÃO CASTELO DE AREIA". DENÚNCIA ANÔNIMA NÃO SUBMETIDA À INVESTIGAÇÃO PRELIMINAR. DESCONEXÃO DOS MOTIVOS DETERMINANTES DA MEDIDA CAUTELAR. QUEBRA DE SIGILO DE DADOS. OFENSA ÀS GARANTIAS CONSTITUCIONAIS. PROCEDIMENTO DE INVESTIGAÇÃO FORMAL. NECESSIDADE DE COMPROVAÇÃO DE MOTIVOS IDÔNEOS. BUSCA GENÉRICA DE DADOS. As garantias do processo penal albergadas na Constituição Federal não toleram o vício da ilegalidade mesmo que produzido em fase embrionária da persecução penal. A denúncia anônima, como bem definida pelo pensamento desta Corte, pode originar procedimentos de apuração de crime, desde que empreendida investigações preliminares e respeitados os limites impostos pelos direitos fundamentais do cidadão, o que leva a considerar imprópria a realização de medidas coercitivas absolutamente genéricas e invasivas à intimidade tendo por fundamento somente este elemento de indicação da prática delituosa. A exigência de fundamentação das decisões judiciais, contida no art. 93, IX, da CR, não se compadece com justificação transversa, utilizada apenas como forma de tangenciar a verdade real e confundir a defesa dos investigados, mesmo que, ao depois, supunha-se estar imbuída dos melhores sentimentos de proteção social. Verificada a incongruência de motivação do ato judicial de deferimento de medida cautelar, in casu, de quebra de sigilo de dados, afigura-se inoportuno o juízo de proporcionalidade nele previsto como garantia de prevalência da segurança social frente ao primado da proteção do direito individual. Ordem concedida em parte, para anular o recebimento da denúncia da Ação Penal n. ${ }^{\circ}$ 2009.61.81.006881-7. (HC 137.349/SP, Rel. Ministra MARIA THEREZA DE ASSIS MOURA, SEXTA TURMA, julgado em 05/04/2011, DJe 30/05/2011).

A ementa acima transcrita refere-se ao julgamento conjunto de dois habeas corpus. O primeiro, com pedido liminar, é o de n. ${ }^{\circ}$ 137.349/SP, e foi impetrado em 27/5/2009 pelos advogados Alberto Zacharias Toron, Carla Vanessa T. H. de Domenico e Claudia Maria Bernasconi, tendo como autoridade coatora desembargadora do Tribunal Regional Federal da $3^{\mathrm{a}}$ Região, relatora do $\mathrm{HC} \mathrm{n}^{\mathrm{o}}$ 2009.03.00.014446-1. O segundo habeas corpus, de n. ${ }^{\circ}$ 159.159/SP, no qual foi requerido e decretado o sigilo dos autos, também com pedido de liminar, foi ajuizado pelos advogados Celso Sanchez Vilardi e Luciano Quintanilha de Almeida e autuado sob o n. ${ }^{0}$ 159.159/SP. 
A despeito do teor da decisão, sintetizada na ementa acima colacionada, é necessário frisar que, quando da análise do pedido liminar do $\mathrm{HC}^{0}$ 137.349/SP, restou registrado que:

\begin{abstract}
Verifico, dentro desse contexto, que a decisão que deferiu a quebra do sigilo telefônico, na verdade, cingiu-se aos dados telefônicos, o que não se confunde com a inviolabilidade das comunicações havidas por telefone. Destaco que a decisão é expressa no sentido de determinar que as empresas operadoras de telefonia forneçam senhas para possibilitar aos agentes federais o acesso aos seus bancos de dados e à obtenção dos dados relativos ao cadastro de assinantes e usuários. Oportuno salientar, ainda, que os elementos que embasaram o início das interceptações telefônicas não estão restritos à denúncia anônima, como querem fazer crer os impetrantes. Com efeito, colho dos autos que, além da denúncia anônima, o procedimento de interceptação telefônica também está lastreado em indícios obtidos a partir de investigações preliminares levadas a efeito pelo Departamento de Polícia Federal.
\end{abstract}

Todavia, no momento da decisão final, preferiu a relatora ignorar tais dados, considerando insuficientes os fundamentos apresentados pelo magistrado de primeiro grau e afirmando a invalidade de todas as provas colhidas a partir da quebra do sigilo telefônico. Frise-se que a primeira medida autorizada judicialmente não foi sequer a interceptação das comunicações telefônicas do investigado, mas apenas a quebra de sigilo de dados telefônicos, já embasada em outros elementos de prova colhidos pela autoridade policial, a partir da qual foram obtidas provas que, juntamente com outros indícios, serviram de alicerce para a autorização das interceptações telefônicas.

A diferença no tratamento recebido pelos “clientes” do sistema penal em nosso país começa, porém, muito antes. A exposição na mídia da prisão de alguns “grandes contraventores”, como usualmente são chamados pela própria imprensa, motivou a edição, pelo Supremo Tribunal Federal, da Súmula Vinculante $n^{0} 11$, referente ao uso de algemas, que prevê:

Só é lícito o uso de algemas em casos de resistência e de fundado receio de fuga ou de perigo à integridade física própria ou alheia, por parte do preso ou de terceiros, justificada a excepcionalidade por escrito, sob pena de responsabilidade disciplinar, civil e penal do agente ou da autoridade e de nulidade da prisão ou do ato processual a que se refere, sem prejuízo da responsabilidade civil do Estado.

Apesar de a decisão de editar a Súmula ter sido, em tese, tomada pela Corte durante o julgamento do Habeas Corpus n ${ }^{\circ} 91952$ - quando foi anulada a condenação do pedreiro Antonio Sérgio da Silva pelo Tribunal do Júri de Laranjal Paulista (SP), pelo fato de ter ele sido mantido algemado durante todo o seu julgamento -, o verdadeiro motivo da edição foi explicitado ainda na mesma ocasião, conforme noticiado no próprio site do STF: “No mesmo julgamento, a Corte decidiu, também, deixar mais explicitado o seu entendimento sobre o uso generalizado de algemas, diante do que considerou uso abusivo, nos últimos tempos, em que pessoas detidas vêm sendo expostas, 
algemadas, aos flashes da mídia”"

Sublinhe-se que, do ponto de vista conceitual, quando as garantias não são aplicadas igualmente para todos os cidadãos elas perdem o seu caráter de garantias, justamente porque muitos indivíduos não terão acesso a elas, o que retira delas o caráter de certeza, necessário à sua configuração. Como citado alhures, para Ferrajoli, o medo ou mesmo a simples desconfiança de um inocente - ou, dito de outra forma, de qualquer inocente - com relação à sua absolvição já é capaz de retirar a legitimidade de todo o sistema.

Aqui cabe ressaltar que o sistema penal de uma determinada sociedade não está ligado apenas ao controle da criminalidade. Vários outros interesses podem influenciar diretamente as práticas penais - por exemplo, a escassez ou abundância de mão de obra. As instituições de controle social visam dissuadir os desempregados - que, perante a fome e as necessidades, se mostram mais propensos a cometer delitos - por meio de penas severas. Por outro lado, em uma sociedade em que os trabalhadores são escassos, a execução penal terá uma função diversa, pois não se trata apenas de impedir que as massas sufocadas pela fome satisfaçam suas necessidades mais elementares. Assim, a execução penal pode se limitar a obrigar ao trabalho os mais resistentes e a ensinar, aos “delinquentes”, que eles devem se contentar com o salário que recebe um "trabalhador honrado" (NEDER, 2012, p. 73).

Além disso, o fato de existir, na prática, uma significativa diferença no tratamento recebido por cada indivíduo ao se deparar com o aparato punitivo estatal, de acordo com a classe social a que pertence, é um fator que colabora com a manutenção - ou até com o agravamento - da desigualdade social existente em nosso país. Isso se deve ao fato de que a simples passagem do indivíduo pelo sistema carcerário marca sua vida para sempre, diminuindo sobremaneira qualquer possibilidade de ascensão social. Ou seja, uma pessoa pobre, que ordinariamente já teria menos oportunidades, ao passar pelo sistema prisional vê serem praticamente eliminadas suas possibilidades de crescimento profissional, além de um sem-número de outras dificuldades criadas pelo estigma do cárcere.

Não é outra a razão do lançamento, pelo Conselho Nacional de Justiça (CNJ), do projeto Começar de Novo, que busca a criação de vagas de trabalho para ex-detentos, para que eles não voltem a delinquir. Segundo estimativas do próprio CNJ, o índice de reincidência no Brasil atualmente varia entre $60 \%$ e $70 \%{ }^{10}$.

Sobre a questão do estigma de determinados grupos de indivíduos, como os ex-presidiários, Goffman (1989, p. 28) esclarece que não são apenas os estigmatizados que sofrem os efeitos da marca

\footnotetext{
${ }^{9}$ Disponível em: <https://goo.gl/QbORZA>. Acesso em: 6 abr. 2016.

${ }^{10}$ Disponível em: <https://goo.gl/T7YPyD>. Acesso em: 10 mar. 2016.
} 
carregada, mas também aqueles que vivem ao seu redor:

Um segundo tipo de pessoa “informada” é o indivíduo que se relaciona com um indivíduo estigmatizado através da estrutura social - uma relação que leva a sociedade mais ampla a considerar ambos como uma só pessoa. Assim, a mulher fiel do paciente mental, a filha do ex-presidiário, o pai do aleijado, o amigo do cego, a família do carrasco, todos estão obrigados a compartilhar um pouco o descrédito do estigmatizado com o qual eles se relacionam.

E cita, ainda, o mencionado autor, um trecho de uma carta enviada a um jornal norteamericano, descrevendo a situação de uma criança de 12 anos que foi excluída de toda atividade social porque seu pai era um ex-presidiário. A menina relatou que tentava ser amável e simpática com todo mundo, mas o preconceito era mais forte: "Minhas colegas de escola me disseram que suas mães não querem que elas andem comigo, pois isso não seria bom para a sua reputação. Os jornais fizeram publicidade negativa de meu pai e apesar de ele ter cumprido sua pena ninguém esquecerá do fato” (GOFFMAN, 1989, p. 29).

A marca deixada pelo cárcere no indivíduo é algo tão profundo, com tantas implicações, especialmente no seu relacionamento social, que é comum que ex-detentos tentem ocultar esse aspecto de seu passado. De fato, são raras as situações em que o fato de já ter estado internado no sistema prisional pode beneficiar uma pessoa ou, mesmo, ser admitido por outras pessoas sem que haja maiores implicações para o ex-presidiário. Por outro lado, o encobrimento do fato quase sempre trará consequências positivas, tendo em vista o preconceito quase generalizado que existe contra os ex-detentos, não só no Brasil, mas na maior parte das sociedades:

\footnotetext{
Devido às grandes gratificações trazidas pelo fato de ser normal, quase todos os que estão numa posição em que o encobrimento é necessário, tentarão fazê-lo em alguma ocasião. Mais ainda, o estigma do indivíduo pode estar relacionado a questões que não convém divulgar a estranhos. Um ex-presidiário, por exemplo, só pode revelar amplamente o seu estigma, prevalecendo-se de maneira imprópria de meros conhecidos, contando-lhes fatos pessoais que vão além do que a relação realmente justifica. Um conflito entre a sinceridade e o decoro será, quase sempre, resolvido em favor desse último (GOFFMAN, 1989, p. 66).
}

Assim sendo, se o sistema penal favorece a internação dos indivíduos de uma determinada classe social nas prisões, certamente esse segmento da sociedade - bem como o grupo de indivíduos que os rodeia, como anteriormente exposto - terá maiores dificuldades em alcançar uma condição econômica mais favorável. Gera-se, desse modo, um círculo vicioso, em que aqueles que não possuem recursos financeiros tendem a ser os criminalizados, os selecionados pelo sistema penal, e a marca gerada por essa seleção colabora de forma decisiva para que continuem socialmente excluídos.

Percebe-se, portanto, que - por mais paradoxal que possa parecer, já que os próprios garantistas defendem que muitos dos problemas combatidos por meio do Direito Penal só podem ser

Revista da Faculdade de Direito - UFPR, Curitiba, vol. 61, n. 3, set./dez. 2016, p. 165 - 187 
resolvidos com uma maior justiça social - o garantismo penal, em nosso país, ajuda a perpetuar as desigualdades econômicas e sociais, pois, na prática, não se aplica a todos. Isto se dá justamente porque, como adrede explicado, ao não serem as garantias constitucionais asseguradas a todos os cidadãos, perde-se o seu caráter de certeza e, desse modo, os direitos fundamentais (especialmente no que tange ao direito penal) acabam funcionando como uma espécie de privilégio ao qual apenas parte da população tem acesso garantido. Fica claro, desse modo, que o garantismo inclui-se na longa linha de teorias e ideologias, importadas pelos pensadores nacionais, mas que aqui adquiriram um novo significado, colaborando mais para a manutenção das estruturas fundamentais de nossa sociedade do que para a sua transformação.

É claro que esse quadro, em nosso país, extrapola os limites do Direito Penal. Situação semelhante ocorre com relação a diversos outros direitos constitucionalmente previstos, que só possuem ampla eficácia para aqueles que podem se valer do Poder Judiciário, especialmente quando representados por advogados de notória competência. Cite-se, apenas como exemplo, os processos referentes à desocupação da localidade conhecida como "Pinheirinho”, bem como a própria operação de retirada dos moradores da área, narrada pelo defensor público Jairo Salvador durante audiência pública $^{11}$. Todavia, é com relação ao Direito Penal que as consequências dessas disparidades são mais preocupantes, justamente em função do estigma deixado, pelo cárcere, na vida dos cidadãos - além de importantes repercussões psicológicas, acaba colaborando para a perpetuação das diferenças econômicas, já que dificulta ainda mais a ascensão social dos indivíduos criminalizados e daqueles que os rodeiam.

\section{CONCLUSÃO}

Ao longo de nossa história um sem-número de conceitos, de países em estágios de desenvolvimento econômico e social completamente diversos, foram importados e aqui reproduzidos, sem qualquer preocupação com a sua aplicabilidade à nossa realidade social. Tal fenômeno deu-se em razão da necessidade de legitimação de nossas instituições, e não em virtude de uma verdadeira preocupação em modificar nossas estruturas sociais. Assim, grande parte das teorias para cá trazidas serviu não como ferramenta de transformação de nossa sociedade, mas, paradoxalmente, como instrumento de manutenção do status quo local, legitimando as estruturas sociais vigentes.

O garantismo penal inclui-se nessa longa linha de teorias e ideologias, importadas pelos pensadores nacionais, mas que aqui adquiriram um novo significado, colaborando mais para a

\footnotetext{
${ }^{11}$ Vídeo disponível em: <https://goo.gl/lC8XbP>. Acesso em: 6 abr. 2016.
} 
conservação das estruturas fundamentais de nossa sociedade do que para a sua transformação.

Sublinhe-se, portanto, que a crítica aqui feita não é direcionada propriamente aos princípios que constituem o garantismo penal, mas sim à transposição deles à realidade brasileira, sem a devida consideração das especificidades de nosso desenvolvimento sociocultural e das diferenças materiais existentes entre o Brasil e os países nos quais a teoria foi produzida e consolidada. Isto faz com que, infelizmente, os princípios do garantismo penal sirvam frequentemente, aqui, para justificar racionalmente a impunidade de uma pequena parcela da população (a mais rica), em vez de garantir a todos a efetivação de direitos constitucionalmente previstos.

Já em uma de suas premissas básicas - a desigualdade de forças entre acusação e defesa -, os autores garantistas nacionais ignoram um aspecto fundamental de nossa sociedade, cuja análise é necessária para a compreensão de nosso sistema penal.

Na relação entre Estado acusador e indivíduo acusado o primeiro dedica apenas uma parte ínfima do total de sua força, buscando a condenação do indivíduo, enquanto o segundo tende a empregar a maior parte de seus recursos - ou até a totalidade -, buscando a sua absolvição. Desse modo, em um país como o Brasil, onde os recursos da polícia judicial são parcos e, apesar de estarmos entre as maiores economias do mundo, a desigualdade na distribuição da renda é enorme, aqueles indivíduos que estão no topo da pirâmide social acabam ficando em uma posição de superioridade em relação à acusação, não por serem mais fortes do que o Estado como um todo, mas por possuírem mais recursos do que aqueles empregados pelo Estado na condenação de um único indivíduo. Entretanto, contraditoriamente, justamente aqueles indivíduos economicamente menos favorecidos é que veem, muitas vezes, suas garantias constitucionais negadas. Ou seja, exatamente aqueles que, na prática, são os mais necessitados, não conseguem ver assegurados seus direitos constitucionais.

Assim, apesar de existirem, em nossa Constituição, diversos dispositivos que garantem um sistema penal de modelo garantista, não podemos dizer que existem, realmente, garantias em nosso Direito Penal, já que, não sendo de fato assegurados para todos os cidadãos, os direitos constitucionais perdem o seu caráter de certeza, necessário à configuração de qualquer garantia. Justamente por não serem garantidos, independentemente da classe social, a todos os cidadãos, os direitos constitucionais em matéria penal funcionam como uma espécie de privilégio, servindo, contraditoriamente, para perpetuar as mesmas estruturas sociais e a desigualdade econômica, já que favorecem a internação, no sistema carcerário, dos indivíduos dos setores menos favorecidos da população, sendo que o estigma deixado pelo cárcere faz com que estes cidadãos, bem como o grupo de indivíduos que os rodeia, tenha ainda menos chances de ascender socialmente.

É necessário lembrar, ainda, que a maioria dos teóricos garantistas nacionais afirma que 
comumente se atribui, ao Direito Penal, a capacidade de lidar com o fenômeno da criminalidade, capacidade esta - asseveram - muito superior à que o direito penal realmente tem, já que o problema da criminalidade tem, como principais fatores, questões econômicas e sociais. Esses autores reconhecem, portanto, que a criminalidade é um problema complexo, com profundas implicações de cunho sociológico. Todavia, o tratamento dela geralmente fica limitado ao âmbito jurídico, já que apenas é criticado o tratamento jurídico-penal dado aos acusados. Esse tipo de análise, porém, não contribui significativamente para a resolução do problema, pois ataca apenas uma das consequências da desigualdade social. Assim, de acordo com o quadro desenhado no decorrer deste trabalho, é necessário ir além de todas as construções meramente jurídicas já feitas sobre o tema, para concluir que a primeira e fundamental reforma a ser feita no sistema penal brasileiro é algo que vai muito além do próprio Direito Penal; ou seja, alcança a distribuição mais racional da renda nacional.

Desse modo, é importante sublinhar que não se está aqui a defender um enrijecimento no sistema penal brasileiro, até porque, como dito acima, a diminuição da violência passa necessariamente pela justiça social. O que deve ser ressaltado é que a forma como os princípios do garantismo penal são aplicados no Brasil é que contribui para a manutenção do status quo. Mas, mais do que isso, e a exemplo do que ocorreu com diversas outras teorias importadas para o nosso território, conforme exposto no capítulo 1, os princípios do garantismo penal ajudam também a legitimar a própria desigualdade de tratamento entre os réus, pois é com base nesse arsenal teórico que são fundamentadas as decisões tomadas, em casos concretos, quando aqueles que tem acesso a uma defesa realmente consistente fazem valer seus direitos constitucionalmente previstos. Ou seja, analisadas individualmente, as referidas decisões estão em perfeita sintonia com os conceitos que embasam o garantismo penal. O que fere a coerência do sistema é que muitos, especialmente os representantes das classes menos afortunadas, não recebem o mesmo tratamento.

Já que foi feita, portanto, uma opção política pela existência das penas privativas de liberdade, é necessário ter em mente que, dentro dessa lógica punitiva, todos devem ser julgados obedecendo-se aos mesmos critérios. Se assim não for, a marca de já ter passado pelo sistema carcerário, a pecha de ex-presidiário, sempre pesará com maior intensidade sobre os mais pobres, o que colaborará para que eles estejam sempre à margem da sociedade.

Seguindo o mesmo raciocínio, há que se perceber que - se a violência está ligada à desigualdade social e, ainda, se a forma como são aplicados os princípios garantistas em nosso país colabora para a legitimação e manutenção desta desigualdade -, obviamente, a práxis do garantismo penal em nosso país contribui para a perpetuação da própria violência. Em suma, ao não serem de fato garantidos, de maneira uniforme a todos os cidadãos, os direitos constitucionalmente previstos, 
não apenas os princípios sobre os quais se ergue o garantismo penal perdem o seu valor, como acabam colaborando para conservar tudo o que, em tese, ele se propõe a combater.

Em um país onde a atual Constituição foi promulgada no ano de 1988 e, curiosamente, ainda subsiste um Código Penal datado de 1940, cujos preceitos colidem frontalmente com os princípios constitucionais, percebe-se a existência de uma antiga realidade, mas revestida de uma nova roupagem: “aos amigos, as garantias constitucionais; aos inimigos, os rigores da lei”.

\section{REFERÊNCIAS}

ABBAGNANO, Nicola. Dicionário de filosofia. 6. ed. São Paulo: Martins Fontes, 2012.

BITENCOURT, Cezar Roberto. Tratado de direito penal: parte geral. v. 1. 21. ed. São Paulo: Saraiva, 2015.

BOBBIO, Norberto. A era dos direitos. Nova ed. Rio de Janeiro: Editora Campus, 2004.

BRANDÃO, Cláudio. Curso de direito penal: parte geral. 2. ed. Rio de Janeiro: Editora Forense, 2010.

CARVALHO, José Murilo de. A formação das almas: o imaginário da República no Brasil. São Paulo: Editora Companhia das Letras, 2011.

CARVALHO, Salo de. Pena e garantias. 3. ed. Rio de Janeiro: Editora Lumen Juris, 2008.

CLASTRES, Pierre. A sociedade contra o Estado. São Paulo: Editora Cosac Naify, 2012.

FAORO, Raymundo. Os donos do poder: formação do patronato político brasileiro. 4. ed. São Paulo: Editora Globo, 2012.

FERRAJOLI, Luigi. Direito e razão: teoria do garantismo penal. 4. ed. São Paulo: Editora Revista dos Tribunais, 2014.

Constitucionalismo principialista e constitucionalismo garantista. In: FERRAJOLI, Luigi; STRECK, Lênio Luiz; TRINDADE, André Karam (Org.). Garantismo, hermenêutica e (neo)constitucionalismo: um debate com Luigi Ferrajoli. Porto Alegre: Editora Livraria do Advogado, 2012. p. 13-56.

GOFFMAN, Erving. Estigma: notas sobre a manipulação da identidade deteriorada. 4. ed. São Paulo: Editora LTC, 1989.

HOBBES, Thomas. Leviatã. São Paulo: Editora Martins Fontes, 2003.

HOLANDA, Sérgio Buarque de. Raízes do Brasil. 27. ed. São Paulo: Companhia das Letras, 2014.

LOPES JUNIOR, Aury. Direito processual penal e sua conformidade constitucional. Vol. 1. 7. ed. Rio de Janeiro: Editora Lúmen Júris, 2011.

Revista da Faculdade de Direito - UFPR, Curitiba, vol. 61, n. 3, set./dez. 2016, p. 165 - 187 
. Investigação preliminar no processo penal. 6. ed. São Paulo: Ed. Saraiva, 2014.

MARINONI, Luiz Guilherme; MITIDIERO, Daniel. O Projeto do CPC: crítica e propostas. São Paulo: Revista dos Tribunais, 2010.

MELLO, Celso Antônio Bandeira de. Curso de direito administrativo. 31. ed. São Paulo: Editora Malheiros, 2014.

NEDER, Gizlene. Discurso jurídico e ordem burguesa no Brasil. 2. ed. Niterói: Eduff, 2012.

Iluminismo jurídico-penal luso-brasileiro: obediência e submissão. Rio de Janeiro: Freitas Bastos, 2000.

SCHMIDT, Andrei Zenkner. Prevencionismo x humanitarismo: uma perspectiva sistêmico-cultural do direito penal. In: Revista de Estudos Criminais. Porto Alegre: Notadez, a. 4, n. 14, 2004.

TASSINARI, Clarissa. Jurisdição e ativismo judicial: limites da atuação do Judiciário. Porto Alegre: Livraria do Advogado, 2012.

THOREAU, Henry. Desobedecendo. Rio de Janeiro: Editora Rocco, 1984.

WEBER, Max. A política como vocação. In: GERTH, H. H.; MILLS, C. Wright (Org.). Max Weber - Ensaios de Sociologia. 5. ed. Rio de Janeiro: Editora Guanabara, 1982. p. 55-89.

\title{
BRAZILIAN WAY OF GARANTISM: A CRITICAL ANALYSIS IN THE LIGHT OF THE PRINCIPLE OF IMMATERIALITY
}

\begin{abstract}
This essay aims to demonstrate, through bibliographic and case law research, that the criminal garantism follows a current of theories that have been imported by national scholars, but here acquired a new meaning, supporting - contrary to the theses' predictions - the conservation of the fundamental structures of our society instead of its transformation. So it is not a set of criticisms against principles of criminal garantism, but an analysis of how these principles have been used in Brazil. The conclusion is that when constitutional guarantees are not uniformly granted to all, they lose their character of guarantees, functioning as a kind of privilege, enjoyed only by those individuals who have the financial means to afford a consistent defense in an eventual prosecution. Thus, the social stigma left by prison mostly affects those individuals belonging to the poorest sections of the society, decreasing significantly their chances of social mobility, as well as the social group around them, thus contributing to the maintenance of social inequality.
\end{abstract}

\section{KEYWORDS}

Garantism. Stigma. Social inequality. 